\title{
estudos da infância: diálogos contemporâneos
}

Estamos diante de um cenário nada aprazível. Depois de um golpe, que levou ao processo de impeachment da presidenta Dilma Rouseff, temos vivenciado um cenário de grave crise política e econômica marcada por significativos cortes e suspensões em diversas áreas, que afetaram sobretudo a educação. Esse processo atingiu de modo categórico e terrível à Universidade do Estado do Rio de Janeiro (UERJ) que vem sendo desprezada pelos atuais governos e, por isso, enfrenta uma situação de precariedade nunca vista em sua história.

Mesmo em condições adversas, nós, do Departamento de Estudos da Infância (DEDI), seguimos resistindo e nos propusemos a organizar, em agosto de 2017, o I Congresso de Estudos da Infância ${ }^{1}$ (CEI), pois trabalhamos por uma educação pública, democrática e popular - marca da UERJ, uma das universidades pioneira no ensino noturno e na política de cotas no Brasil. E, mesmo em tempo de não normalidade, consideramos imprescindível a continuidade de um intercâmbio científico multidisciplinar e interdisciplinar a respeito da infância e das crianças. Dentro desse contexto, entendemos que o CEI representa uma forma de resistência e de luta pela universidade.

O Congresso é parte de uma proposta maior que se inicia com a inauguração em 1976 da Faculdade de Educação no $12^{\circ}$ andar no campus Maracanã. É neste espaço de profusão de conhecimentos teórico-práticos que em 2005 foi criado o Departamento de Estudos da Infância. O DEDI, assim carinhosamente chamado, é o único departamento acadêmico de "Estudos da Infância" no Brasil. Por tratar especificamente das questões da infância e das crianças em suas dimensões filosóficas, sociais, políticas, ideológicas, econômicas e culturais, passa a ocupar um lugar político-epistemológico na estrutura de uma universidade pioneira no campo da Educação, por tratar especificamente das questões da infância e das crianças em suas dimensões sociais, políticas, ideológicas, econômicas e culturais. O trabalho desenvolvido no DEDI caracteriza-

\footnotetext{
${ }^{1}$ Agradecemos ao CNPQ e à CAPES o apoio financeiro dispensado para realização deste evento.
} 
se por pensar e investigar a infância para além dos muros da escola e das relações familiares, ou seja, considerando sua amplitude, complexidade e especificidade. É um debate amplo e complexo porque também envolve a educação escolar das crianças de 0 a 10 anos e a formação de professores para atuar nessa etapa da Educação Básica. Ademais, trata da infância e das instituições com o propósito de articular e compreender as interfaces da cultura e das políticas públicas, sobretudo aquelas destinadas à infância, promoção de direitos, produção cultural voltada para as e das crianças e as relações entre infância, mídia e tecnologias. A infância enquanto categoria do pensamento e enquanto as possibilidades que abre para pensar tanto a experiência humana quanto as possibilidades e impossibilidades da educação (em um sentido amplo) enriquece as variadas abordagens desde as quais ela é tratada no Departamento.

A complexidade deste debate está presente neste dossiê - "Estudos da Infância: diálogos contemporâneos" -, que se vincula a essa história e a partir deste contexto reuniu pesquisadoras e pesquisadores dos estudos da infância a fim de estabelecer diálogos que contribuam na, com e para a reflexão acerca dos vínculos que são estabelecidos com a infância, que permitam compreender os modos como as crianças habitam o mundo e o que elas têm a dizer acerca deste mundo. Tratase, portanto, de um dossiê que reúne artigos de alta qualidade acerca das complexas relações que envolvem as crianças - tanto como sujeito como geração e os modos contemporâneos de pensá-las e pensar a categoria da infância.

O artigo que abre esse dossiê, de Maria Letícia Nascimento e intitulado "Estudo da infância e desafios da pesquisa: estranhamento e interdependência, complexidade e interdisciplinaridade", apresenta, a partir da sociologia da infância, análises a respeito das crianças como sujeitos históricos e de direitos, atores sociais, produtores de cultura, compreensão que é resultado de uma construção social. A autora esclarece que é a partir dos estudos da infância que se passa a compreender e defender que a infância é uma geração específica que produz e reproduz a vida social, um reconhecimento da categoria dentro de uma estrutura geracional e que sofre com as interferências das forças econômicas e políticas. 
Assim, a pesquisa da e com a infância revela tanto a interdependência entre crianças e adultos quanto evidencia as relações de poder estabelecidas.

Contempla está edição o artigo, "Infância, Experiência e Educação: apontamentos a partir de reflexões sobre a pequena infância", de Eloisa Acires Candal Rocha e Márcia Buss-Simão. As autoras analisam e refletem sobre a infância e a experiência a partir da área da educação e, particularmente, das ponderações em torno das pesquisas com crianças pequenas e da educação infantil. O sentido de experiência apresentado pelas autoras, toma as principais teorias educacionais ou projetos educativos para a educação na infância, marcando os contornos da experiência educativa, na e da infância institucionalizada, como uma experiência social a partir de estudos empíricos que dão visibilidade às ações das crianças como parte de suas vidas nos coletivos infantis.

Em uma homenagem à memória de Fúlvia Rosemberg, que iniciou o texto com Renata Lopes Costa Prado e Maria Cristina Gonçalves Vincenrin, as três autoras do artigo "Ética na Pesquisa com Crianças: uma revisão da Literatura Brasileira das Ciências Humanas e Sociais" debatem sobre os avanços e obstáculos na ética em pesquisa com seres humanos no contexto nacional. Trata-se de uma análise de artigos e capítulos de livros brasileiros que discutem o tema, focalizando, sobretudo, os vínculos entre política e ciência; a desigual relação de poder adultocriança, a construção de procedimentos que permitam uma efetiva escuta das crianças e a participação destas nos processos de investigação. As autoras sustentam que não bastam normas éticas para assegurar às crianças o lugar de atores sociais, pois é necessário uma nova compreensão da posição delas, desta geração e do/a próprio/a pesquisador/as.

Por meio do artigo "Crianças inventando mundos e a si mesmas: ideias para pensar a autoria narrativa infantil", e apoiada em uma abordagem crítica, a pesquisadora Gilka Girardello promove uma reflexão acerca da importância e das possibilidades de valorização da autoria narrativa infantil no cenário contemporâneo, considerando o papel que desempenham a imaginação e as experiências vividas pelas crianças no processo de narrar/ouvir/construir uma história. Neste trabalho, a autora assume uma perspectiva que desloca o "ouvir 
história" de uma concepção meramente passiva para outra que foca na atividade e agência daquele/a que escuta e faz suas elaborações a partir do que ouve, do que é narrado. O texto faz uma crítica à noção de autoria como fundação ou propriedade, apoiando-se em uma dimensão ético-poética para a construção do conceito, entendido como um fazer discursivo no qual as crianças exploram a linguagem e a imaginação tanto para a invenção de histórias como para sua própria constituição como sujeitos. Para a construção do seu argumento, a autora conta com as experiências de crianças cujas narrativas são extraídas do projeto de elaboração coletiva de um livro, e com a análise de fragmentos de memórias de infâncias de conhecidos/as e importantes ficcionistas.

De forma muito apurada, Patrícia Tavares Raffaini, com o artigo "A escrita compartilhada. Monteiro Lobato, Rãzinha e a Reforma da Natureza", faz uma análise das correspondências que Monteiro Lobato manteve com inúmeros leitores em todo o Brasil, com atenção especial a um conjunto específico de cartas que o escritor recebeu da menina Maria de Lurdes. A autora revela que por meio das cartas é possível perceber vários aspectos de como a leitura era feita, o cotidiano das crianças e dos jovens, suas opiniões sobre política e a consonância de Lobato bem como a recepção de sua obra pelo seu público leitor.

Em "Pedro Bloch: um escutador da graça das crianças", Camila Rodrigues analisa as anedotas contadas e publicadas por este médico, jornalista e escritor. A autora revela que muitas das anedotas foram recolhidas por ele próprio nas conversas com seus pequenos pacientes no seu consultório. Essas publicações incentivavam seus leitores e conhecidos adultos a ouvir as crianças como outra experiência de percepção do mundo.

Tendo como pano de fundo o recreio, Lucia Rabello de Castro, com seu artigo "Precisamos falar do recreio!" - A construção do comum pelas crianças na escola", que aproxima os campos da infância e da política, nos convida a pensar no recreio como um tempo e espaço escolar em que as crianças têm a possibilidade de construir coletivamente sentidos sobre sua condição geracional em contraposição a uma lógica escolar que privilegia o desempenho individual e competitivo. A 
autora analisa o recreio como um dispositivo pelo qual as crianças instituem pontos de vista singulares em uma coletividade.

María Teresa Suárez explora a possibilidade de escutar "outras" vozes a partir de experiências filosóficas, realizadas com jovens com capacidades diversas em uma escola que integra o programa Escuelas Taller - Herramientas para la paz em Colômbia. Em seu artigo "Infâncias: vocês desde la diversidade", convida a entrar na infância, considerada uma dimensão da experiência humana para além da idade cronológica. A categoria de estrangeiro lhe possibilita refletir sobre a necessidade de se abrir ao desconhecido para poder acolher ao Outro e sobre a necessidade de renunciar à intenção formativa para que o diálogo seja possível.

Suzana Santos Libardi e Marit Ursin, com o artigo "Escutando os adultos sobre proteção da infância e das crianças em situação de rua no Brasil urbano", concebem a criança como sujeito ativo na sociedade e refletem sobre como os adultos percebem as crianças brasileiras que vivem no espaço urbano e em um contexto de rua. A partir de uma pesquisa teórico-empírica as autoras buscam compreender as causa que estão por trás desse "fenômeno" e como os adultos veem o dever de proteção da infância aplicado a essas crianças.

Compreender as crianças do campo, é o tema tratado por Levindo Diniz Carvalho e Rogério Correia da Silva, no artigo "Infâncias no Campo: brinquedo, brincadeira e cultura". Para os autores é importante se questionar sobre: "Como compreender a experiência da brincadeira como um fenômeno cultural? De que forma é possível perceber a brincadeira e os aspectos sociais e humanos vividos pelas crianças quando brincam? E o que nos revelam as brincadeiras das crianças dos chamados povos campo e/ou comunidades tradicionais?" A diversidade de infâncias é marcada por relações com pessoas, território e práticas que precisam ser consideradas e entendidas a partir das suas culturas.

E "O que dizem as crianças ribeirinhas da Vila do Piriá - Curralinho/PA acerca de suas práticas culturais"? Simei Santos Andrade, Magali dos Reis e Laura Maria Silva Araújo Alves apresentam o estudo sobre as Infâncias da Amazônia, com destaque para a infância e as crianças ribeirinhas. A investigação, realizada no distrito Vila do Piriá no município de Curralinho no Pará da Amazônia Marajoara, tem como 
interlocutores crianças entre 5 a 11 anos. As autoras apresentam as práticas culturais vivenciadas pelas crianças no cotidiano de uma região de água e floresta, as relações entre elas e suas histórias, como, por exemplo, sobre andar de canoa, pescar, caçar, apanhar açaí e colocar matapi.

Finalizamos esse dossiê com os questionamento trazidos pelo artigo "Gêneros, sexualidades e infâncias: cenas de crianças na contramão da inocência", de Raquel Gonçalves Salgado e Leonardo Lemos de Souza, que põem em debate a aura sagrada e secular da inocência em torno da infância, combinada ao discurso sobre o desenvolvimento infantil, que afirma "verdades" sobre os modos como as crianças devem viver a infância. Considerando o gênero e a sexualidade os autores se debruçam sobre as experiências, os conhecimentos e os sentidos que as crianças compartilham em suas produções culturais lúdicas, recolhidos em uma pesquisa empírica realizada em instituições de Educação Infantil da rede pública municipal de ensino de Rondonópolis, Mato Grosso, Brasil.

Os artigos que aqui apresentamos denotam um trabalho cuidadoso e atento à infância. A partir deles, convidamos ao leitor a se adentrar nesse sutil universo que nos interroga tanto quanto adultos quanto como educadores. Esperamos uma ótima leitura e que o dossiê Estudos da Infância: diálogos contemporâneos possa fomentar o debate e oferecer contribuições teórico-empíricas importantes para os estudos da infância.

Um grande abraço,

Beatriz Fabiana Olarieta

Conceição Firmina Seixas Silva

Lisandra Ogg Gomes

Rita Marisa Ribes Pereira 